\title{
Numerical Staged Construction Analysis of Precast Concrete Bridge
}

Ana Cecília Ferreira Leite, Fernando Artur Nogueira Silva, Romildo Alves Berenguer and Romilde Almeida de Oliveira

Department of Civil Engineering, Catholic University of Pernambuco, Recife 51110-200, Brazil

\begin{abstract}
The paper discussed about the staged construction analysis of two-span precast-girder bridge considering time dependent effects, namely creep and aging of concrete. Results obtained showed that it is very important to consider construction stage in the analysis of bridge because of stress resultants which are important in design process and very different from those obtained without the consideration of construction stage. This fact is especially important for bridges, because construction period continues along time and loads may change during the construction period and after.
\end{abstract}

Key words: Staged construction analysis, reinforced concrete bridge.

\section{Introduction}

The construction of a precast concrete bridge is a hard and complex process, which involves different buildings techniques that can lead to structural problems if they are not taken into account with caution [1].

An realistic analysis of a bridge construction has to consider not only the final stage but also the development of the several stages that are required to erect the bridge, which plays an important role on the their overall behavior [2]. The paper discusses the modelling of construction stage of a two-span precast-girder bridge through nonlinear staged constructions modeling, taking into account the effects of time on structural concrete, such as creep, shrinkage and aging of concrete.

\section{Finite Element Analysis}

Finite element models are commonly considered in the design and project phase of the important engineering structures, such as bridges, using some special software. In this study, SAP2000 Finite

Corresponding author: Romildo Alves Berenguer, professor, research fields: concrete, corrosion materials and structural concrete.
Element Program [3], which is used for linear and non-linear, static and dynamic analyses of 3D models of structures, is used in the analysis.

The bridge has fixed bearings at the bent, which restrain vertical, longitudinal and transverse translation. Sliding bearings at the abutments restrain vertical and transverse translation. For all other bearing degrees of freedom, it was necessary to add small stiffness to stabilize the girder before the deck is erected.

The three dimensional finite element model is shown in Fig. 1. The model has 676 nodal points and 2.048 area elements to model the deck. In addition, 340 frame elements are used to represent girders and piers. Entire finite element model have 3.788 equilibrium equation.

\subsection{Modelling of the Construction Stages}

The following construction stages are considered in performed analysis:

- add and load girders;

- add deck shell elements;

- reduce the stiffness of deck shell elements to simulate concrete placement;

- apply the deck dead load; 


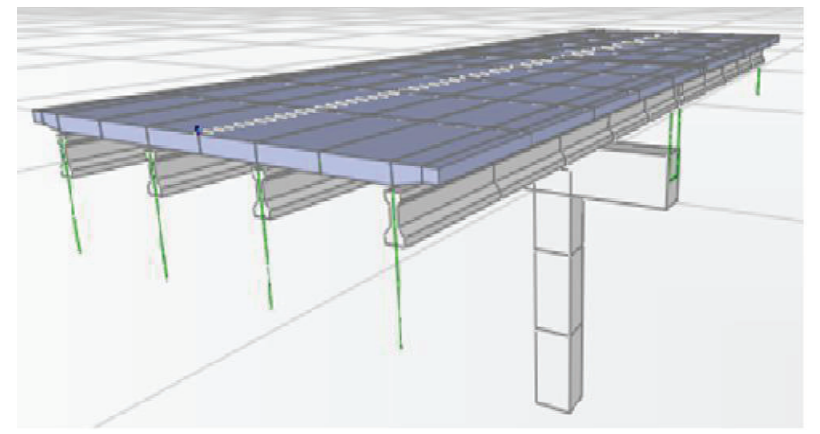

Fig. 1 Finite element model.

- reset the stiffness of the deck shell elements to simulate the hardening of concrete;

- add continuity links to the model.

A time dependent analysis of the construction procedure and a period of five years after the end of the construction of the bridge were performed.

\subsection{Time Dependent Material Properties}

In the construction stage analysis of bridges, time dependent material properties such as elasticity modulus, creep and shrinkage for concrete should be considered, because they are variable due to the climate during construction [4].

\subsubsection{Compressive Strength}

The compressive strength of concrete at an age $t$ depends on the type of cement, temperature and curing conditions. The relative compressive strength of concrete at a specified age may be calculated by the following Eq. (1) [5]:

$$
f_{c m}(t)=\beta_{c c}(t) f_{c m}
$$

where, $\beta_{c c}(t)$ is a coefficient with dependence on the age of concrete and is calculated by Eq. (2):

$$
\beta c c(t)=\exp \left(s\left\lfloor 1-(28 / t)^{1 / 2}\right\rfloor\right)
$$

where, $f_{c m}(t)$ is the mean concrete compressive strength at an age of $t$ days; $f_{c m}$ is the mean compressive strength after 28 days; $t$ is the age of concrete in days and $s$ is a coefficient with $0.20,0.25$ and 0.38 types of cement. Fig. 2 shows the variation of the coefficient $\beta_{c c}(t)$ with the time for all types of cements found in Brazil.

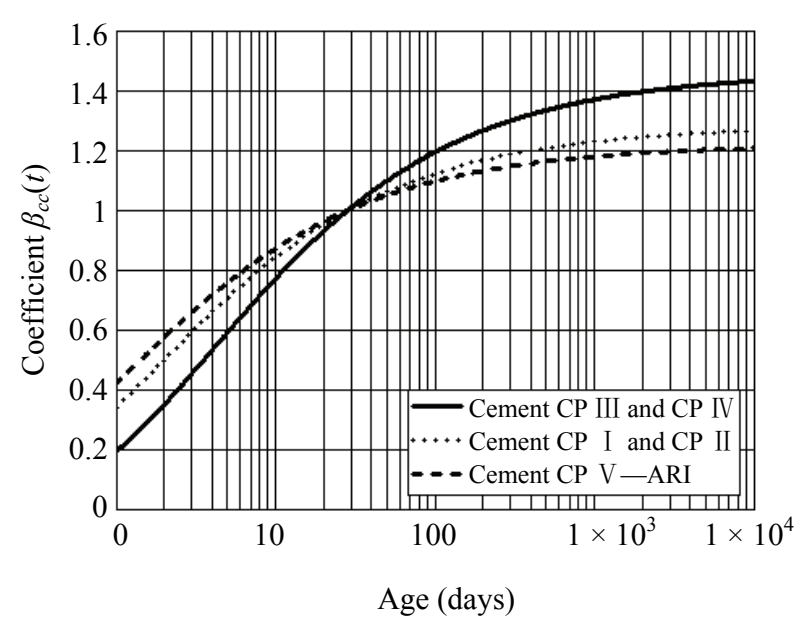

Fig. 2 Evolution of coefficient $\beta_{c c}(t)$ with time.

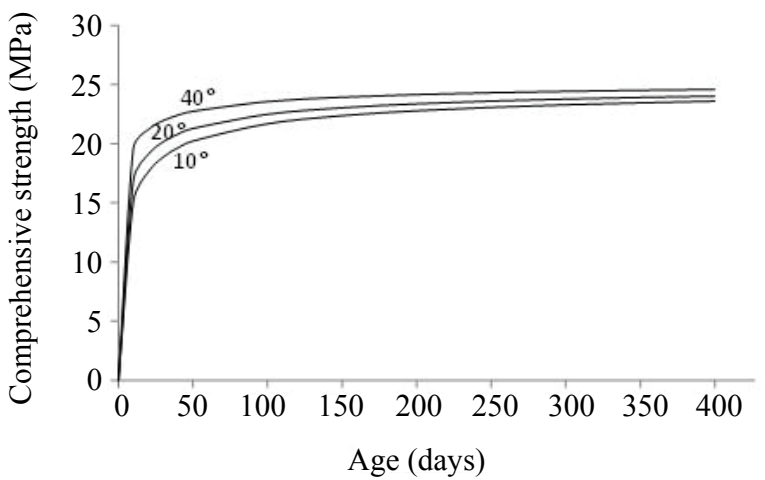

Fig. 3 Evolution of compressive strength with time and curing temperature.

$$
t_{e}=\sum_{i=1}^{n} \Delta t_{i} \exp \left[13.65-\frac{4,000}{273+T_{i}}\right]
$$

where, $\Delta t_{i}$ is the amount of days that the curing temperature was maintained equal to $T_{i}$.

Fig. 3 shows the evolution of compressive strength with time and curing temperature, from where it can be seen that the higher curing temperature, the higher will be compressive strength, mainly in early ages. Analysis are performed with a concrete with $50 \mathrm{MPa}$ of characteristic concrete strength.

\subsubsection{Aging of Concrete}

The modulus of elasticity of concrete changes with time. According to CEB [5], the value of the modulus of elasticity in a specified age can be calculated by Eq. (4):

$$
E_{c}(t)=\left[\beta_{c c}(t)\right]^{1 / 2} E_{c}
$$


where, $E_{c}(t)$ is the modulus of elasticity at age of $t$ days; $E_{c}$ is the modulus of elasticity at an age of 28 days; $\beta_{c c}(t)$ is a coefficient which depends on the age of concrete. Fig. 4 shows a comparison of the evolution of compressive strength and modulus of elasticity with time, where it can be seen that, for a given age, the modulus of elasticity is more mature than the strength.

\subsubsection{Shrinkage of Concrete}

The shrinkage of concrete can be defined as the volumetric strain that the material develops when it is not subjected to loading or deformations restraints.

Strain on concrete, developed by the free shrinkage between initial time $t_{0}$ and final time $t$ can be calculated by Eq. (5) [5]:

$$
\varepsilon_{s c}\left(t, t_{0}\right)=\varepsilon_{s c \infty}\left[\beta_{s}(t)-\beta_{s}\left(t_{0}\right)\right]
$$

where, $\varepsilon_{s c \infty}$ is the final value of the shrinkage; $\beta_{s}$ is the coefficient to describe the development of shrinkage with time; $t$ is the age of concrete in days and $t_{0}$ is the age of concrete in days at the beginning of shrinkage (usually considered as 0 ).

The final value of the shrinkage $\varepsilon_{c s \infty}$ depends on the relative humidity of the ambient atmosphere (\%), the slump of concrete and the notional size of member which is being analyzed. Figs. 5 and 6 show the variation of the shrinkage coefficient with slump and relative humidity and the notional size, respectively. For small values of the relative humidity, the strain, due

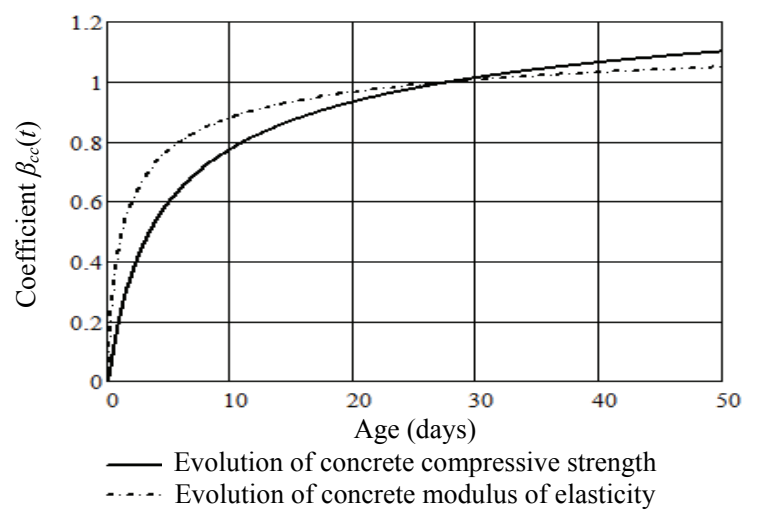

Fig. 4 Evolution of compressive strength and modulus of elasticity with time. to shrinkage, increases with the increasing of the slump and the difference becomes less significant when the relative humidity values increase (Fig. 5). Regarding the notional size, it can be seen that the smaller its value, the higher will be the corresponding shrinkage strain coefficient.

\subsubsection{Creep}

When concrete undergoes long terms loads, it remains to deform over the time even when the stress level is kept constant. This phenomenon is called creep. According to CEB-FIP Model Code [5], for a constant stress applied at time $t_{0}$, this leads $t$ :

$$
\varepsilon_{c c}\left(t, t_{0}\right)=\frac{\sigma_{c}}{E_{c 28}} \varphi\left(t, t_{0}\right)
$$

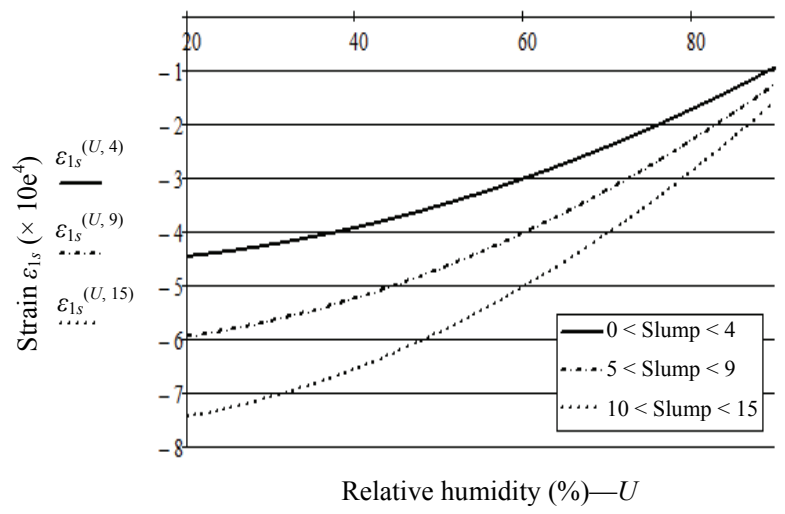

Fig. 5 Variation of shrinkage coefficient $\varepsilon_{c s \infty \infty}$ with the slump and relative humidity.

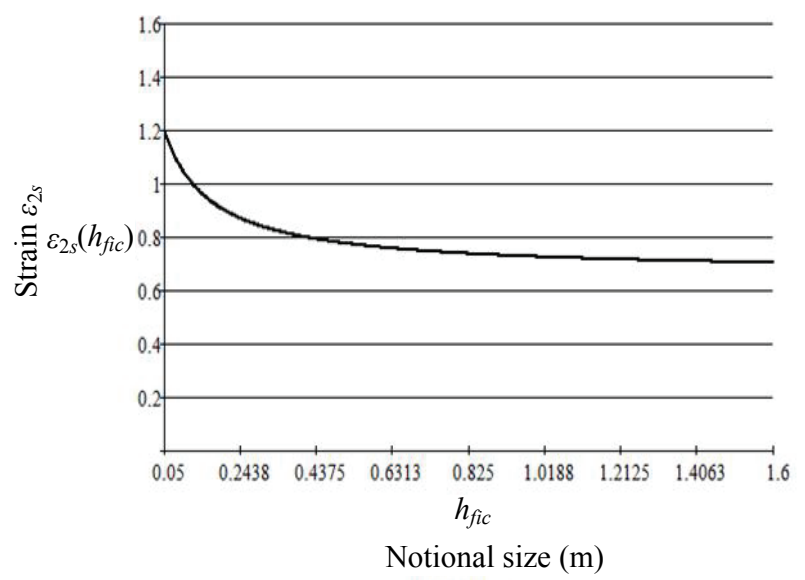

Fig. 6 Variation of shrinkage coefficient $\varepsilon_{c s \infty o}$ with the notional size of the member. 
where, $\sigma_{c}\left(t_{0}\right)$ is the stress at an age of loading $t_{0} ; \phi\left(t, t_{0}\right)$ is the creep coefficient and is calculated from Eq. (7):

$$
\varphi\left(t, t_{0}\right)=\varphi_{a}+\varphi_{f \circ o}\left[\beta_{f}(t)-\beta_{f}\left(t_{0}\right)\right]+\varphi_{d}
$$

where, $t$ is the age of concrete in the instant you want to calculate the creep strain (in days); $t_{0}$ is the age of concrete when total load is applied (in days); $\varphi_{a}$ is the rapid creep coefficient; $\varphi_{f \circ}$ is the final irreversible creep coefficient; $\beta_{f}$ is the coefficient that evaluates the development of creep with time.

Creep coefficient is also influenced by the relative humidity, by the slump and by the notional size of the member in a similar fashion to that reported for shrinkage strains. It is shown below the time dependent material properties used in the analysis of the bridge:

- cement type, $s=0.25$;

- relative humidity $(\%)=50 \%$;

- notional size, $h(\mathrm{~mm})=100$.

Shrinkage strains were not taken into account in the analysis because reinforcement that is often present in reinforced concrete elements is not modeled in finite element analysis performed. Research considering reinforcement modeling is in progress.

\section{Numerical Results}

Fig. 7 gives the bending moments along the bridge deck in the case the construction stage procedure is considered and is not considered, respectively.

Results obtained show that the construction stages affect in an important way of the bending moments along the bridge deck. If the construction stage is considered, bending moments increase around $60 \%$ when compared with the results obtained when the construction stage is not considered in the analysis. Observing Fig. 7, one can see that what really occurs is a redistribution of bending moments along the deck of the bridge with negative bending moments being higher, when the constructions stage is considered, and positive bending moments being lower. The observed behavior shows clearly the importance of considering the construction stage on design. Shear forces along deck length are shown in Fig. 8. As it can be seen, the behavior was not the same observed in bending moments diagram in Fig. 7. The differences are observed in shear forces when construction stage is considered and when it is not taken into account.

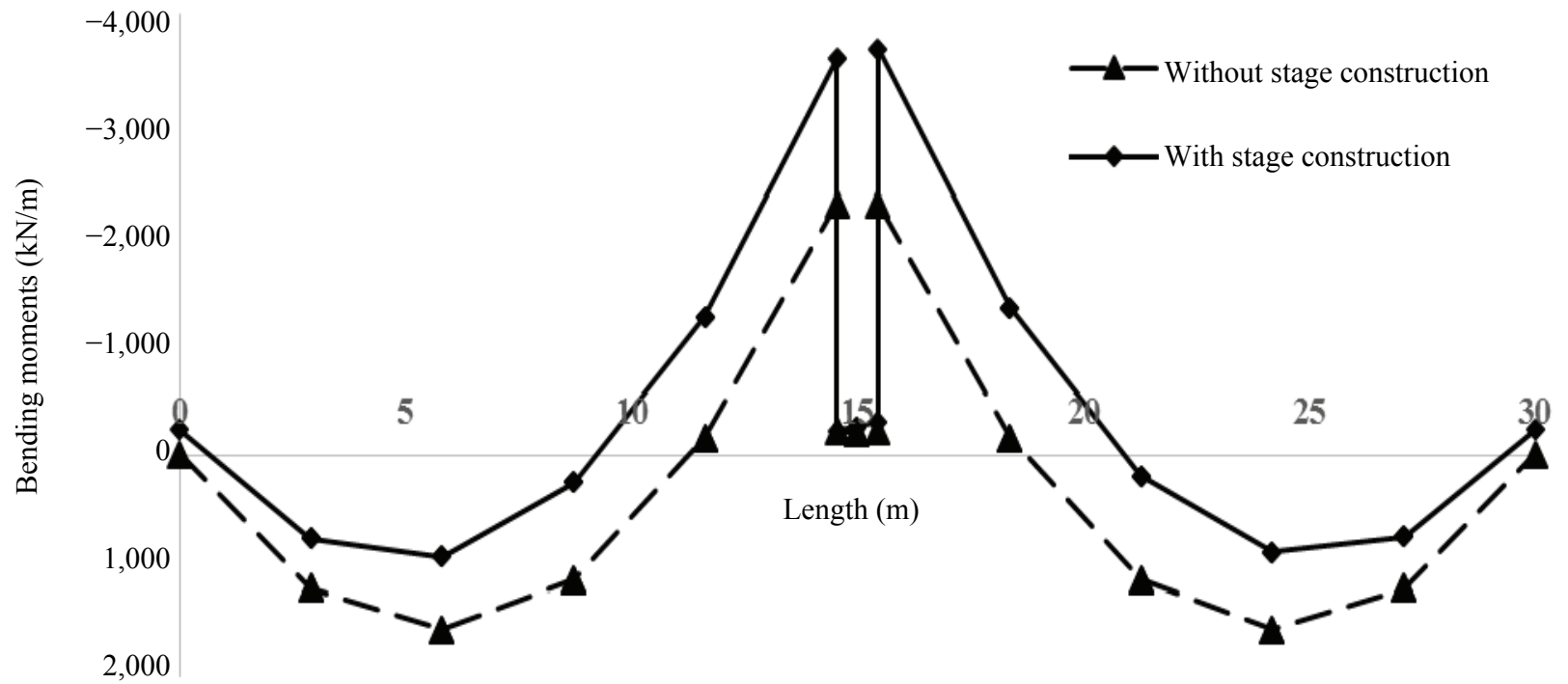

Fig. 7 Bending moments along bridge deck. 


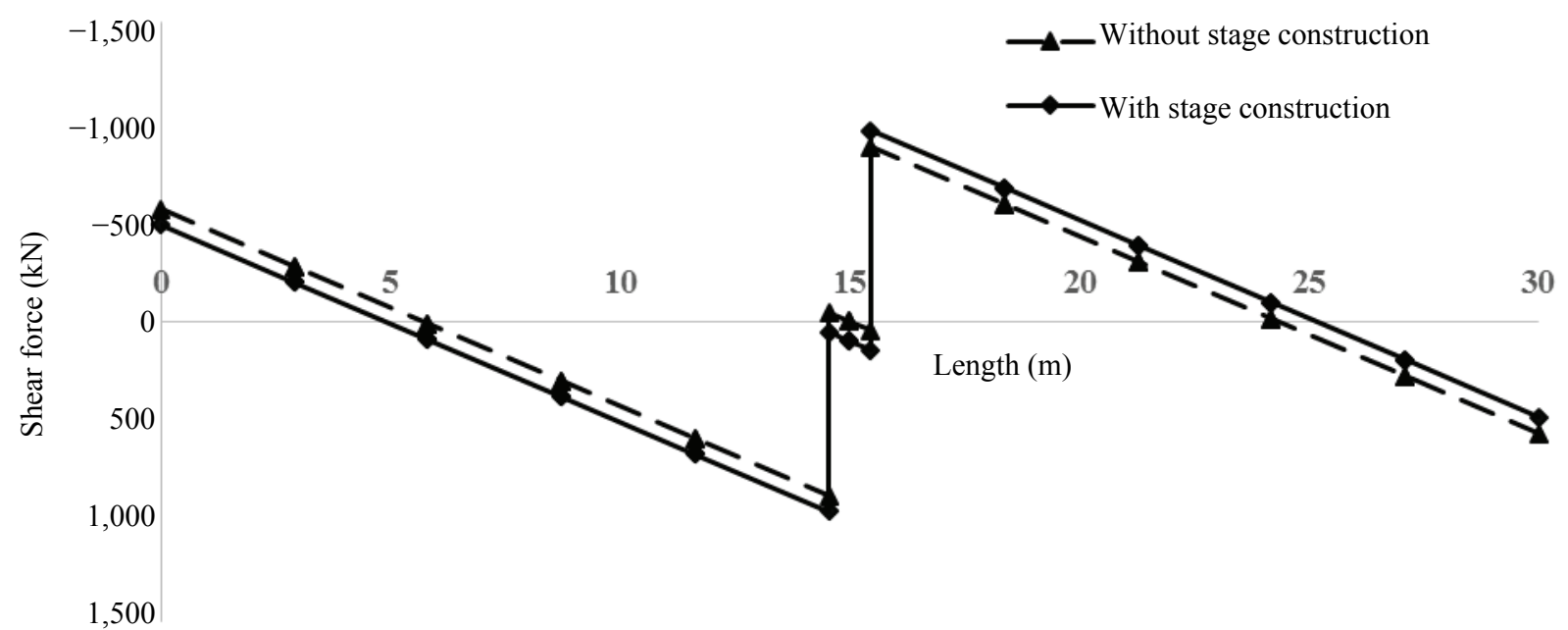

Fig. 8 Shear forces along bridge deck.

\section{Conclusions}

The paper discussed about the staged construction analysis of two-span precast-girder bridge considering time dependent effects, namely creep and aging of concrete.

Analysis were performed in SAP2000 using bridge and staged construction module. Results obtained from analysis performed can be summarized as follows:

(1) Bending moments are strongly affected by construction stages. Differences greater than $60 \%$ in negative bending moments were observed, when construction stages are considered;

(2) Unlike the bending moments, shear forces did not exhibit important differences among the analysis with and without the consideration of construction stages.

The results obtained show that it is very important to consider construction stage in the analysis of bridge because stress resultants that are important in design process are very different from those obtained without the consideration of construction stage. This fact is especially important for bridges, because construction period continues along time and loads may change during the construction period and after.

\section{References}

[1] Mari, A. R. 2000. "Numerical Simulation of the Segmental Construction of Three Dimensional Concrete Frames.” Eng. Struct. 22 (2000): 585-96.

[2] Ketchum, M. A. 1986. Redistribution of Stresses in Segmentally Erected Prestressed Concrete Bridges. Report No. UCB/SESM-86/07, Department of Civil Engineering, University of California, Berkeley.

[3] Computers and Structures Inc. 2008. SAP2000, Integrated Finite Element Analysis and Design of Structures. California: Computers and Structures Inc.

[4] Cruz, P. J. S., Mari, A. R., and Roca, P. 1998. "Nonlinear Time-Dependent Analysis of Segmentally Constructed Structures.” J. Struct. Eng. 124 (3): 278-88.

[5] CEB (Comite Euro-International du Beton). 1990. CEB-FIP Model Code. London: Thomas Telford Ltd. 